\title{
O Trágico na Filosofia do Amor DE GeORg SimMeL
}

\author{
Vera Serra Lopes ${ }^{1}$ \\ (Mestranda em Filosofia, Faculdade de Letras, Universidade de Lisboa)
}

\section{Considerações iniciais}

No presente trabalho apresentaremos sucintamente a filosofia do amor de Simmel, a partir de três textos: Fragmento sobre o Amor, Nota sobre o Eros platónico e o Eros moderno e Fragmentos e Aforismos, escritos na fase madura do pensamento de Simmel, a Lebensphilosophie, e publicados postumamente entre 1921 e 1922. Na parte final exploraremos a ideia do trágico na filosofia do amor.

O leque de temas abordados pela filosofia de Simmel é realmente muito vasto, de tal modo que arriscamos dizer que qualquer pessoa encontrará pelo menos um tema de interesse abordado pela filosofia do autor alemão. Num mundo como o nosso actual (trágico) em que a interdisciplinaridade se faz cada vez mais presente, mais fundamental e simultaneamente mais perigosa, Simmel é um pensador extremamente importante.

Simmel é um filósofo a título pleno, embora não incorra na pretensão megalómana de reduzir tudo a um princípio primeiro único, atitude esta que o filósofo diagnostica como sendo a tendência da filosofia, derivada daquela mais nobre exigência de unidade que o filósofo sente. Simmel tem uma só questão fundamental ao longo de toda a sua obra: a vida e as suas formas. A sua filosofia é uma filosofia da vida e, como tal, pretende pensar as mais variadas expressões e dimensões dessa vida. Exactamente por ser

\footnotetext{
${ }^{1}$ veraserralopespimenta@gmail.com
}

Philosophica, 46, Lisboa, 2015, pp. 53-65. 
uma filosofia da vida, esta aborda tudo aquilo que dela provém, incluindo a própria morte. O carácter orgânico da sua filosofia faz com que ao tratarmos do amor ou de qualquer outro tema estejamos, de certa forma, a tratar o todo da sua filosofia ou, pelo menos, o seu núcleo fundamental. Encontramos em cada pequena parte o todo e no todo, todas as partes únicas, indivisíveis e insuperáveis.

\section{O amor em Simmel}

O amor raramente foi considerado um tema da filosofia: não era próprio de um filósofo pensar no amor. O amor era, como nos diz Schopenhauer na sua Metafísica do Amor, um assunto para poetas:

Em vez de causar admiração que um filósofo procure também ocupar-se deste tema, alvo eterno de todos os poetas, deve antes ser motivo de admiração que um problema que na vida humana seja tão importante, não tenha sido, até agora, tido em consideração pelos filósofos, e nos apresente como matéria que ninguém tenha ainda tratado. ${ }^{2}$

À parte Platão, poucos filósofos reconheceram ao amor a dignidade e a importância que Simmel the reconheceu, nem lhe dedicaram as páginas que até Simmel nos faltavam. O amor e os sentimentos em geral foram negligenciados pelos filósofos, senão mesmo intencionalmente afastados da filosofia. Muito sucintamente, e segundo a perspectiva simmeliana, o amor em Platão era um meio para atingir a ideia de beleza e a imortalidade, e em Schopenhauer este tinha todas as suas raízes no instinto sexual; era, nas palavras do próprio, "vontade da espécie". Contudo, Simmel herdou de Platão a tarefa de desvendar o mistério do amor, para lá da realidade imediatamente dada, do acidental, para além do desejo sensual, para além da mera relação afectiva. $\mathrm{O}$ amor passa a estar ao abrigo da metafísica e com ele a individualidade. $\mathrm{O}$ amor moderno também encontrou no amor algo de atemporal, mas o que ele não pode fazer é localizá-lo para além do vivido imediato.

A frase com que Simmel abre o seu Fragmento sobre o Amor, diz-nos o seguinte: "É entre o Eu e o Tu que, aos olhos da consciência humana, se produz o primeiro dos seus conflitos e a primeira das suas unificações." ${ }^{3}$

2 Schopenhauer, Metafisica do Amor, Lisboa, Guimarães, 2002, pp. 11-12.

3 G. Simmel, Fragmento sobre o Amor e Outros Textos, trad. Maria João Costa Pereira, Lisboa, Relógio d'Água, 2004, p. 69. Nesta tradução o termo que aparece para "Konflikt" é "dissensão", mas preferimos a tradução literal, sendo que o conflito é um conceito fundamental da filosofia sociológica de Simmel. 
Esta citação põe-nos já a caminho de perceber um dos aspectos trágicos do amor. Por agora, fiquemos apenas com a ideia de que o Eu e o Tu são, sob a perspectiva da consciência humana, o lugar (não mensurável) da primeira cisão, do conflito e também da sua unificação.

Segundo este modo de pensar o nosso comportamento estaria perante uma alternativa: poderia apenas ser egoísta ou altruísta. A totalidade das acções humanas esgotar-se-ia nesta dicotomia em que ou o Eu visa o próprio $\mathrm{Eu}$ ou o Eu visa o Tu. A polarização da realidade nestas duas atitudes opostas é falaciosa e insuficiente, se queremos englobar todas as relações possíveis. Há várias situações em que não são considerados, exclusivamente, nem o Eu nem o Tu. Existe algo mais para além destas duas realidades opostas. O egoísmo, tal como o altruísmo, implica sempre uma orientação teleológica (um objectivo, um fim) que não existe, por exemplo, na esfera do instinto; este pode dirigir-se para o $\mathrm{Eu}$, para um $\mathrm{Tu}$ ou mesmo ir contra o Eu. A esfera do comportamento instintivo encontra-se aquém deste dualismo e também não pode ser encaixada nas categorias do egoísmo e altruísmo.

$\mathrm{O}$ agir "por amor"4 pertence a uma outra esfera que se encontra para além da referida alternativa. O amor é um movimento do espírito, da vida, que está para além de um privilégio do $\mathrm{Eu}$ ou do Tu. Neste agir por amor estão envolvidas pulsão e satisfação próprias; o seu fim não é apenas o Tu, mas não é mero egoísmo, pois é acompanhado de uma certa "abnegação de si”, ainda que não haja dissolução do indivíduo, como há, eventualmente, na comunhão mística.

Simmel, e o seu pensamento orgânico, opõe-se entusiasticamente a todo o tipo de concepções mecanicistas. $\mathrm{O}$ amor tem, em geral, uma natureza tal que não se deixa decompor nestes termos, "esse agir, na sua origem mais profunda, é demasiado uno e inteiro para aparecer como uma espécie de mistura mecânica dos dois tipos de motivações." ${ }^{15}$ É também neste sentido que Simmel se opõe à "psicologia racionalista", segundo a qual ou o amor deriva do máximo altruísmo ou este é fundamentalmente egoísta.

No pensamento de Simmel encontramos uma tentativa de superar os dualismos rígidos, polares. Há sem dúvida uma busca de unidade, porventura despedaçada na época moderna, é evidente a tentativa de encontrar uma outra esfera, um terceiro elemento. $\mathrm{O}$ amor enquadra-se nesta outra esfera, numa esfera ideal, aparece como um terceiro que está para lá destes

\footnotetext{
4 "Se, por intermédio desses casos simples, compreendermos correctamente que o nosso agir pode ser independente em relação à alternativa acima referida, chegaremos também a projectar-nos nessa relação mais complexa, e, no entanto, capaz de reduzir a sua acuidade, em que se move o agir «por amor» (Handeln «aus Liebe»).” Ibid., p. 71.

5 Ibid., p. 71.
} 
dualismos. Há contudo, como referimos, a recusa de uma solução de tipo mecanicista, artificial, típico da bricolage filosófica que supõe reconciliar os opostos através da técnica do corte e costura.

O amor é um sentimento sui generis onde, numa determinada acção, o impulso se confunde com o objectivo, a motivação com o conteúdo. E isto muito mais no amor do que em qualquer outra actividade do espírito.

[...] o amor por um ser humano, enquanto motivação por assim dizer geral de uma determinada acção, solidariza-se com o seu conteúdo, irriga-o com o seu sangue muito mais directamente do que em qualquer outra motivação (com excepção, talvez, do ódio). [...] Aqui o carácter da acção benéfica, essa tensão entre o Eu e o Tu, e o seu próprio querer-viver flui, para lá desse hiato, rumo ao outro, abolida toda a distância, sem precisar de um ponto que separe ao mesmo tempo que una. ${ }^{6}$

A espontaneidade é característica do amor, que é directo, não-teórico, imediato. $\mathrm{O}$ amor não precisa deste ponto que separa ao mesmo tempo que une, pois ele próprio é esse ponto, esse dar-se imediato e recíproco.

O milagre do amor é justamente não abolir o ser-para-si nem do Eu nem do Tu, fazer dele inclusive a condição que permite essa supressão (Aufhebung) da distância, esse egoísta fechar-se em si mesmo do querer-viver. O que é algo totalmente irracional, que se subtrai à lógica das categorias habitualmente válidas. ${ }^{?}$

O amor é uma categoria ${ }^{8}$. Não é ingénuo que Simmel o trate assim; para um kantiano usar o termo "categoria" para classificar o amor, tem de querer dizer qualquer coisa e pode querer dizer, antes de Heidegger, que o entendimento não tem primazia sobre as outras "faculdades" da alma, ao utilizar o termo faculdade estamos já a cair no reino da teoria e o amor consiste em algo totalmente irracional sob ponto de vista das categorias com que normalmente pensamos.

Schopenhauer, por exemplo, pretende explicar esta supressão (neste caso é mesmo uma supressão que temos e não uma superação) através da unidade transcendental do ser. É uma solução de tipo racionalista que é fruto da sua incompreensão do amor, da essência do amor. Para Schopenhauer o amor era a procriação, manifestação da vontade, continuar da espécie, tal como se vê na sua Metafísica do Amor, mas o amor é exactamente liberta-

6 Ibid., p. 72.

7 Ibid., p. 72.

8 "O amor é uma categoria primordial, não tendo qualquer outro fundamento além de si próprio", Ibid., p. 80. 
ção dessa esfera biológica, de onde aliás deriva, em parte, a sua dimensão trágica e tanto mais quanto mais moderno for.

A abordagem do amor, tal como é efectuada por Georg Simmel, significa a oposição a todo o intelectualismo ${ }^{9}$. O abandono do primado da teoria sobre a praxis, muito característico da filosofia do século XX ou de uma determinada contra-corrente do século XX, inspirada pela filosofia do século XIX de Schopenhauer e Nietzsche. Estas são filosofias que se debruçam sobre a vida, sobre a existência, em que se fala de algo que nos diz directamente respeito, que experienciamos e vivemos efectivamente. Simmel pretende refutar a possibilidade de "compor" o amor a partir de uma multiplicidade de factores, nenhum dos quais justamente é amor. ${ }^{10} \mathrm{~A}$ diversidade de manifestações que apelidamos de amor (como o amor pela paisagem, por Deus, por uma Obra de Arte, etc.) não contraria a sua unidade essencial, de que Simmel nos quer falar, mas pelo contrário prova-a. Tem de haver um núcleo imutável que dê origem a esta profusão infinita de acontecimentos, uma certa Esfera Ideal em que se encontra o amor.

Referimos o amor pela Paisagem. Simmel dá-nos o exemplo do amor pela paisagem de Florença e diz-nos que este é independente do facto de gostarmos de lá viver (do "desfrute subjectivo"-prático) bem como da contemplação estética ("juízo de valor objectivo") que esta nos proporciona. $\mathrm{O}$ mesmo se passa, por exemplo, no erotismo sexual; este consiste em "amarmos também o corpo do outro, nesse sentido de não nos contentarmos com "desejá-lo" e contemplá-lo de um ponto de vista estético"11. O que Simmel nos quer mostrar é que o amor está desvinculado da prático, da teoria e de toda a valoração, e surpreendentemente esta possibilidade acentua-se na época moderna, tal como nos diz nos seus Fragmentos e Aforismos. "Vemos esse amor emergir de profundezas totalmente irracionais da vida, sem que vise necessariamente qualquer melhoria ou deterioração dessa vida"12, e sem isto significar que o amor está abaixo de outras actividades do espírito.

9 “Assim como inúmeras vezes o nosso intelecto não consegue penetrar uma unidade pela compreensão, e tem portanto de fragmentá-la em vários elementos a partir de um pressentimento, de uma exigência ou de uma intuição, para reconquistá-la em seguida a título de «unidade sintética» pela reunião desses elementos, assim também a nossa realidade afectiva surge frequentemente como algo uno e inteiro em si, mas que, mal chega à superfície da nossa vida prática (em todos os sentidos do termo) e estando diversamente desenvolvido, se divide numa multiplicidade de sentimentos particulares. No entanto, se nos ativermos à sua unidade, percebê-lo-emos como uma cooperação, uma complementaridade, uma imbricação desses elementos diferenciados. Não se trata de análise intelectual (se bem que possa também sê-lo), mas de evolução afectiva vivida." Ibid., p. 74.

10 Ibid., p. 75.

11 Ibid., p. 76.

12 Ibid., p. 76. 
O amor é um puro estado/movimento do sujeito no qual está presente também o teor factual do objecto e com isto, embora o amor seja uma actividade criadora do sujeito que cria, por assim dizer, o seu amor, Simmel quer salvaguardar uma certa dimensão sensível do amor, e sobretudo uma integridade do objecto, do $\mathrm{Tu}$ (como tinha feito, de forma diferente Feuerbach). Este é um ponto em que, segundo Simmel, o eros platónico e o amor moderno divergem. Os gregos não tinham ainda, como os modernos, consciência de uma subjectividade criadora.

A relação (sendo que o termo relação como nos diz o filósofo indica já um dualismo e uma relação exterior a ambos os pontos do binómio ${ }^{13}$ ) dá-se entre a alma e o mundo, imanência e transcendência, sujeito e objecto. Não há em Simmel qualquer idealismo solipsista. Amando o objecto na sua "incomparabilidade transcendental":

damos uma forma acabada à relação fundamental entre a alma e o mundo: a alma permanece decerto fixada ao seu centro - [...] mas essa imanência é a forma em que ela se torna transcendente, capaz de apreender os conteúdos do mundo e integrá-los em si. Se ela não fosse, primeiramente, em si, não poderia sair de si mesma; mas essa formulação, inevitavelmente cronológica, não designa uma sucessão que separa, mas sim a determinação da vida, fundamentalmente unitária. ${ }^{14}$

A alma, sujeito ou amante tem um centro próprio, é imanente, mas em virtude desta imanência ela torna-se transcendência, movimento do interior para o exterior, em que apreende os conteúdos do mundo e os integra na sua esfera própria. Este movimento não é um movimento cronológico, mas o movimento da Vida, processo unitário. "Primeiramente" não indica um momento temporal, em que a alma seria primeiro imanente e depois transcendente; quando dizemos que primeiramente a alma é una, que é uma unidade em-si, está desde logo implícito o movimento uno e simultâneo, da própria vida, para fora de si. O Amor é, neste sentido, uma actividade formativa que "dá forma ao existente"; joga-se tudo neste jogo entre

13 "Noto, sob a sua superfície, os indícios de uma relação das almas - «relação» é já uma expressão dualista e falsificadora -, uma unidade dual, um absoluto de estar juntos, de evoluir juntos, que não é amor. Este é já distanciamento, confronto, suposição do ser-para-si - e, simultaneamente, a tentativa de superá-lo. Essa tentativa está votada ao fracasso: uma vez tendo tomado posse dessa «relação», a consciência faz dela realmente uma relação, leva-a à sua forma antitética própria. Se esses esforços fossem bem-sucedidos, o amor deixaria justamente de existir e em vez dele existiria essa outra coisa; [...] Colocando o amor diante de si - tornando-se assim amor empírico - , surge a sua problemática e a sua contradição. Há algo no seu fundamento a partir do qual se desenvolve a dualidade." Ibid.., p. 141.

14 Ibid., p. 77. 
a "valência" em si de sujeito e objecto e, por outro lado, numa actividade criadora do sujeito que em cada caso dá forma ao objecto.

Simmel afirma: "O ser humano que eu contemplo e conheço, que temo ou venero, aquele que a obra de arte modelou, é de cada vez um produto particular" ${ }^{15}$. E prossegue dizendo que se o consideramos em tudo igual, isso deve-se a uma atitude intelectual, pois não há um objecto (sujeito) à partida e depois múltiplas situações em que ele se encontra. $\mathrm{O}$ amor "cria o seu objecto como produto totalmente original." ${ }^{16}$ É certo que o Tu existe e é conhecido antes de ser amado, mas o amado não é já esse Tu, pré-existente, ele é algo de novo ${ }^{17, *}$

[...] Parece-me da maior importância reconhecer o amor, como uma função imanente, diria eu formativa da vida psíquica, activando-se também seguramente a partir de uma incitação do mundo, mas nada determinando quanto aos portadores dessa incitação. Este sentimento está mais completamente ligado à unidade que engloba a vida do que muitos, talvez a maioria dos outros. ${ }^{18}$

Amante e Amado, Eu e Tu, Sujeito e Objecto, a quo e ad quem, o amor dá-se imediatamente na relação (simultânea) destes opostos; todos se integram num só processo, unitário ${ }^{19}$. Simmel diz-nos, no seu Nota sobre o Eros platónico e o Eros moderno, que para o amor que afasta a individualidade (o platónico), a reciprocidade é um elemento secundário, meramente acessório. Enquanto para o amor moderno a "reciprocidade" é essencial. O Eros grego era fundamentalmente desejo, um querer ter. $\mathrm{O}$ amor aparecia

15 Ibid., p. 78.

16 Ibid., p. 78.

17 "é preciso, por certo, antes do mais, que o ser humano exista e seja conhecido, antes de ser amado. Mas então esse algo que acontece não tem lugar com esse ser existente que permaneceria não modificado; pelo contrário, foi no sujeito que uma nova categoria fundamental se tornou criadora. O outro é 'o meu amor', com tanta mais razão quanto é 'a minha representação'; não é um elemento invariável que entraria em todas as configurações possíveis e, portanto, na situação de ser amado, ou ao qual viria a acrescentar-se de certa forma o amor, mas um produto original e unitário que antes não existia." Ibid., p. 79.

18 Ibid., p. 81.

19 "Por mais longe que olhemos, não há nenhum outro sentimento com o qual a absoluta interioridade do sujeito faça tender de maneira tão integral a sua vida para o absoluto do seu objecto, integrando-se o terminus a quo e o terminus ad quem, apesar da sua oposição insuperável, incondicionalmente a uma só corrente, que nenhuma instância intermediária vem em parte alguma ampliar, embora de início uma instância desse género tenha guiado um pouco a corrente e ainda mantenha de modo algo acidental um canal lateral de ligação." Ibid., p. 85. 
então como um estado intermédio entre o ter e o não-ter e extinguir-se-ia com o ter. $\mathrm{O}$ amor não é posse, nem mesmo aspiração a possuir; ele "deseja" a correspondência, "deseja" sentir-se amado mas não pretende possuir e apoderar-se do objecto amado.

Para o amor moderno o objectivo verdadeiro é o amor correspondido, sendo tudo o que se lhe segue secundário e acidental, ele compreendeu - ou seja, é a consequência desse conhecimento - que há no outro algo impossível de conquistar, que o absoluto do eu individual ergue uma muralha entre os seres humanos, muralha essa que mesmo a mais apaixonada vontade de ambos não seria capaz de demolir, e que faz de o "ter" real, que queira ser mais do que a realidade e a consciência de ser amado, uma ilusão. ${ }^{20}$

O Amor Moderno é a consequência do reconhecimento de que o outro é uma individualidade imperscrutável, indomável. É neste sentido que o amor não deixa de parte a ideia da reciprocidade, mas antes a advoga. Em Platão o amor como desejo de imortalidade demonstra a indiferença entre eu e tu que a sua teoria supunha. Não há cisão, não há indivíduo, não há nem Eu nem Tu; em Platão, há uma total "indiferença". A individualidade é, por um lado uma unidade indecomponível, dedutível, subsumível e, por outro, quando introduzida num mundo, ela é desmontável, fragmentada, calculável, obedecendo a leis gerais. Para o pensamento racional, a individualidade é assustadora, com a sua insubmissão, as suas leis próprias, o seu certo grau de arbitrariedade, contudo Platão, que pretendia evitar a volatilização do amor, ao pôr de parte a individualidade, acabou por volatilizá-lo no universal. A individualidade é, segundo Simmel, o foco do amor, o "conceito moderno de amor" está "arraigado na individualidade concreta.". O mistério é a relação desta individualidade com o mundo e no amor entre dois é o embate de duas individualidades.

Tal como na ética simmeliana encontramos a "lei individual" que se contrapõe ao imperativo geral e abstracto de Kant, devemos encontrar no amor uma lei individual do erotismo:

na relação incomparável entre indivíduos não comparáveis reside um significado inteiramente limitado a essa relação, mas que supera a sua fenomenalidade superficial - que não é dominada ou justificada por uma ideia geral da beleza, do valor, do que é digno de amor, mas justamente pela simples ideia dessas existências individuais e da sua consumação. ${ }^{21}$

\footnotetext{
$20 \quad$ Ibid., p. 110.

${ }^{21}$ Ibid., p. 113.
} 


\section{O trágico na Filosofia do Amor}

Tendo compreendido isto, passemos à análise propriamente dita daquilo em que consiste o trágico para Simmel e de que forma é que o encontramos no amor.

Em O Conceito e a Tragédia da Cultura de 1919, o filósofo diz-nos:

[...] destino trágico - ao contrário de um destino triste ou destruidor vindo de fora - nós denominamos o seguinte: que as forças de destruição dirigidas contra um ser tenham origem nas camadas profundas desse mesmo ser; que com a sua destruição um destino que provém dele mesmo se realize e seja, por assim dizer, o desenvolvimento lógico da estrutura com a qual o ser construiu a sua positividade. ${ }^{22}$

O trágico é então algo que necessária e invariavelmente provém do processo da vida, uma negação da vida que provém dela. O trágico deriva fundamentalmente do embate com a individualidade e de uma individualidade que pode contrariar a corrente vital de onde provém. No amor isso torna-se claro, como veremos.

A vida produz formas, fá-lo contínua e incessantemente, como diz Simmel em $O$ Conflito da Cultura Moderna: a sua imagem exterior não pode ser senão formas, portanto, ela produz necessariamente (sublinhamos a ideia de necessidade, fundamental para que se compreenda o trágico) formas, pontos fechados, unos, indivisíveis. Inicialmente estes espelham-na, dão-lhe forma, mas, com o decorrer do processo vital, tendem a autonomizar-se, a cortar o fio que as mantinha ligadas à vida de onde provêm.

Vejamos então como se passam as coisas no amor e como está muito próximo da ideia da tragédia da cultura.

Aqui [...] reside o fenómeno trágico fundamental: o de que a vida cria uma forma indispensável para si, que lhe é de resto insuportável, mas que, pelo simples facto de ser forma, é hostil tanto em relação à mobilidade como à individualidade da vida. ${ }^{23}$

Há dois aspectos trágicos no amor: por um lado, tal como nos outros movimentos do espírito, há uma tendência para anular a individualidade, mas ele surge apenas quando inflamado por esta individualidade; por outro lado, o amor volta-se contra a vida a partir da qual se originou.

22 G. Simmel, La Tragédie de la culture, Rivages, 1988, p. 211.

23 G. Simmel, Fragmento sobre o Amor e Outros Textos, p. 143. 
O primeiro aspecto trágico do amor é que este é fundamentalmente individual, mas não pode aceitar o carácter insuperável dessa mesma individualidade $^{24}$. O amor moderno ama uma determinada individualidade mas ele não pode admitir a oposição entre Eu e Tu, "no seu puro ser-si" o amor:

contém já algo do trágico, pois há uma contradição entre a interioridade indissolúvel do sentimento no seu portador e o envolvimento, a absorção do outro, e a necessidade de fundir-se com ele, contradição no processo entre o eu e o tu, que mesmo essa última instância não pode preservar de um perpétuo recomeço. ${ }^{25}$

Simmel comenta Romeu e Julieta de Shakespeare afirmando que a sua tragédia é justamente a medida do seu amor, este não tem lugar no mundo empírico mas uma vez que provém desse mundo e deve, forçosamente, entrelaçar o seu percurso real na condicionalidade desse mesmo mundo, então vê-se perante uma contradição mortal.

Um outro aspecto trágico do amor é a sua autonomia em relação à vida. $\mathrm{O}$ amor provém da própria vida que é um fluxo contínuo, um ser sempre mais vida mesmo no seu sentido biológico, mas o amor dá-se para além disto, embatendo com a vida de onde provém, emancipando-se dela. O amor moderno liberta-se de servir a vida reprodutiva, o mundo da praxis, etc. Sinal disso é que, por exemplo, cada vez mais dizia-nos Simmel (com um optimismo que talvez hoje nos surpreenda) se atentam as qualidades espirituais do parceiro em detrimento da sua competência biológica. Neste fenómeno reside a sua máxima elevação e também o seu maior perigo.

Mas o que o amor com certeza recusa totalmente é o interesse pela reprodução da espécie. Como o ser que ama, se libertou enquanto tal de toda a relação propriamente finalística, da relação hedonista e egoísta, e como a relação moralista e altruísta não pode deixar de apegar-se ao seu estado, que é simplesmente um ser e não um agir, assim também a relação finalística ao serviço da espécie lhe é igualmente estranha. Não é um ponto de passagem, mas um ponto final, ou melhor, o seu ser e o seu sentimento de si estão absolutamente além de toda a noção de caminho e de objectivo final, de toda a propensão a servir de meio ou a servir-se de um meio, do mesmo modo que o conteúdo da fé religiosa e a obra de arte: simplesmente, nestes últimos casos, a forma duradoura dada a uma produção torna mais clara do que no amor a distância em relação à teleologia da vida. Talvez isso permita ouvir essa tonalidade trágica geral que emana de todo o grande apaixonado e de todo o grande amor, tanto mais

\footnotetext{
24 “[...] o amor é trágico no estado mais puro: inflama-se apenas em contacto com a individualidade, e choca contra a impossibilidade de superar a individualidade" Ibid., p. 142.

25 Ibid., p. 94.
} 
perceptível neste último quanto mais nitidamente separado do desenrolar racional da vida, tanto mais inevitável quando o amor se fecha neste e se mescla naquela, como no casamento. ${ }^{26}$

$\mathrm{O}$ amor encontra a sua proveniência precisamente na vida da espécie, mas uma contradição interna, uma tendência para a auto-destruição inflama-o, a partir do momento em que tendo ganho existência própria se desligou da sua origem, da sua finalidade inicial.

Estes dois aspectos do trágico, presentes no amor, estão muito relacionados com a ideia da tragédia da cultura, que é o predomínio do objectivo sobre o subjectivo. Os objectos culturais, por assim dizer, tornam-se válidos em si e por si e deixam de servir a vida e a elevação da alma humana que é característico da cultura ${ }^{27}$. A tragédia da cultura consiste exactamente na tendência e na pretensão de autonomia das formas em relação à vida da qual surgiram e que inicialmente as animou. $\mathrm{O}$ amor, tal como as outras esferas ideais, e aliás mais do que estas, testemunha contra a própria vida $^{28}$, pois é algo que diz sobretudo respeito ao sujeito que ama, independentemente da vida e particularmente da vida e teleologia da espécie, o que favorece e inflama a individualidade "central ou total" 29 , e neste sentido o choque entre duas individualidades, eu e tu.

Esta tragicidade que encontramos no amor é, no fundo, a tragédia da existência; esta é sempre imanente ao próprio sujeito ${ }^{30}$.

26 Ibid., p. 92.

27 "Pertence ao conceito de toda a cultura o facto de o espírito criar algo objetivo e independente por onde passa o desenvolvimento do sujeito de si para si mesmo; mas, por isso mesmo, este elemento integrador que condiciona a cultura é predeterminado por um desenvolvimento específico, que consome sempre as forças do sujeito, que os atrai sempre para a sua órbita sem os conduzir assim ao máximo de si mesmos: o desenvolvimento do sujeito já não pode tomar o mesmo caminho que o desenvolvimento do objeto; se o faz ainda assim, entra numa rua sem saída ou no esvaziamento da vida mais íntima e mais própria." Antonio Carlos Santos (trad.). "O conceito e a tragédia da cultura, de Georg Simmel”. Crítica Cultural - Critic, Palhoça, SC, v. 9, n. 1, p. 145-162, jan./jun. 2014, p. 160.

28 “elas surgem da própria vida, pois é próprio da sua essência mais profunda superar-se e criar a partir de si o que não é ela, colocar o seu outro, de maneira criadora, em face do seu próprio desenrolar e da sua própria legalidade."; "o puro conceito do amor, o movimento que leva um sujeito ao outro, desligado de tudo o que é vida da espécie e que permanece inteiramente dentro do sujeito, enquanto sentimento absolutamente individual [...]." G. Simmel, Fragmento sobre o Amor e Outros Textos, p. 100.

29 "O desenvolvimento crescente do erotismo favorece o investimento e a exigência do puro indivíduo, isto é, do sujeito central ou total" Ibid., p. 101.

30 "Se o trágico não significa simplesmente o choque de forças ou ideias, de volições ou exigências opostas, mas sobretudo o facto de que o que destrói uma vida se desenvolveu 
Pelas suas próprias forças e pelo seu desenvolvimento finalístico, esta impele para o alto a plenitude do amor; mas no instante em que desabrocha, o amor exala o seu perfume numa região de liberdade, bem para além do seu enraizamento. Não se trata decerto de uma tragédia com destruição e desenlace fatal. Mas é esta a contradição: ao lado ou acima da vida que tudo quer englobar, há alguma coisa que lhe é estranha, que se destaca da sua corrente criadora, que retira da sua própria semente fortuna e infortúnio, e que não obstante vem justamente de uma profunda vontade, ou necessidade, ou melhor, talvez, de um dever dessa mesma vida, e essa alienação em relação a ele representa o seu próprio e último segredo; essa contradição, essa negação, sem agressividade decerto, da vida, que é negação de si, faz a doce música trágica soar diante da porta do amor. ${ }^{31}$

$\mathrm{O}$ amor tornou-se mais que vida, mais do que a vida, este faz parte de uma camada, não totalmente sólida, que não se cristaliza necessariamente embora resida aí o grande perigo. É preciso partir da vida para sair dela e a ela retornar ${ }^{32}$.

a partir de uma necessidade última dessa mesma vida, de que a trágica «contradição com o mundo» é, em última instância, uma contradição interna do próprio sujeito - então todos os habitantes do reino da ideia carregam esse fardo." Ibid., p. 92.

31 Ibid., pp. 93, 94.

32 “....] o grande problema do espírito moderno: tudo o que, pelo seu próprio sentido, vai para além dos dados dos fenómenos vitais deve encontrar um lugar no seu próprio interior, em vez de se transportar para um exterior igualmente espacial. Não se trata de síntese do finito e do infinito, mas de unidade natural da vida." Ibid., p. 112. 


\title{
RESUMO
}

No presente artigo apresentaremos sucintamente em que consiste aquilo a que chamamos a filosofia do amor de Simmel, a partir de três textos: Fragmento sobre o Amor, Nota sobre o Eros platónico e o Eros moderno e Fragmentos e Aforismos, textos publicados entre 1921 e 1922. Na parte final do artigo exploraremos a ideia do trágico na filosofia do amor. No amor, tal como nos outros movimentos do espírito, há uma tendência para anular a individualidade mas ele surge apenas quando inflamado por esta individualidade. O amor (moderno) é fundamentalmente individual e simultaneamente não pode aceitar o carácter insuperável dessa mesma individualidade.

Palavras-chave: Georg Simmel - filosofia do amor - individualidade - vida - tragédia

\begin{abstract}
In questo articolo presenteremo sinteticamente la filosofia dell'amore di Simmel, a partire da tre testi: Frammento sull'Amore, L'Eros platonico e l'eros moderno e Frammenti e Aforismi, testi publicati tra il 1921 e il 1922. Nella parte finale dell'articolo analizzeremo l'idea del tragico nella filosofia dell'amore. Nell'amore, come negli altri movimenti dello spirito, c'è una tendenza ad annullare l'individualità, ma esso sorge solo quando ne è infiammato. L'amore (moderno) è fondamentalmente individuale, e allo stesso tempo non può accettare il carattere insuperabile di questa stessa individualità.
\end{abstract}

Parole chiavi: Georg Simmel - filosofia dell'amore - individualità - vita - tragedia

\begin{abstract}
In this article, we'll briefly present Simmels Philosophy of Love, based on three texts: On Love (A Fragment), Eros platonic and modern and Fragments and Aphorisms, texts published in 1921/1922. In the final part of the article we will analyze the idea of the tragic in the philosophy of love. In love, as in other movements of the spirit, there is a trend to erase individuality, but love arises only when aroused by it. Modern love is fundamentally individual, and simultaneously it cannot accept the insuperable character of this precise individuality.
\end{abstract}

Key-words: Georg Simmel - philosophy of love - individuality - life - tragedy 